\title{
Failure Mechanism and Effect of Nozzle Parameters on Abrasive Water Jet Rock Breaking
}

\author{
Jialiang Liu $\mathbb{D}^{1,2}$ Yujie Zhu $\mathbb{D}^{1,2}$ and Shujian Du $\mathbb{D}^{1,2}$ \\ ${ }^{1}$ State Key Laboratory of Mountain Bridge and Tunnel Engineering, Chongqing Jiaotong University, Chongqing 400074, China \\ ${ }^{2}$ Civil Engineering College, Chongqing Jiaotong University, Chongqing 400074, China \\ Correspondence should be addressed to Jialiang Liu; liujialiang@cqjtu.edu.cn
}

Received 1 December 2020; Revised 28 February 2021; Accepted 13 March 2021; Published 31 March 2021

Academic Editor: Radoslaw Zimroz

Copyright (c) 2021 Jialiang Liu et al. This is an open access article distributed under the Creative Commons Attribution License, which permits unrestricted use, distribution, and reproduction in any medium, provided the original work is properly cited.

\begin{abstract}
Abrasive Water Jet (AWJ) technology has vast application prospects in the assisted drill-blasting of tunnel excavation, with the advantages of fast-breaking speed, low tool wear, less dust, and good mobility. Nevertheless, AWJ technology has some limitations and shortcomings, such as the small effective fracturing range and parameter mismatch, which influence the fracturing effect of AWJ. To solve the abovementioned issues, it is necessary to study the failure mechanism of rock impacted by AWJ and nozzle parameter effects on rock fragmentation. Based on the coupling algorithm of Smooth Particle Hydrodynamics and Finite Element Method (SPH-FEM), in this research, the numerical model of AWJ impacting rock was established, and the result was verified with Computed Tomography (CT) scanning after the AWJ impacting rock experiment and image processing technology. Through the analysis of the stress characteristics of typical particles in the rock model at different stages and positions, the formation and expansion mechanisms of the crater and the cracks were revealed. Additionally, in this research, the comprehensive damage factor of rock $(X)$ representing the fragmentation degree was defined. By comparatively analyzing $X$-values with certain technical parameters of AWJ, the importance ranking of the nozzle parameters, the effect of each nozzle parameter on the rock fragmentation, and the optimal parameter combination were also investigated.
\end{abstract}

\section{Introduction}

A tunnel is an engineering structure for underground passage, and tunnels play an important role in communications and transportation. Drill-blasting method and mechanical crushing technology, as the widely used technologies in tunnel excavation, have many key defects $[1,2]$. The drill-blasting method has problems such as a complex procedure, high labor intensity, difficulty of controlling excess underexcavation, and low safety. Mechanical crushing technology has some problems such as poor geological adaptability and an incomplete excavating range. Abrasive Water Jet (AWJ) technology is a frontier method equipped with the advantages of fast-breaking speed, low tool wear, less dust, and good mobility, and it is suitable for the assisted drill-blasting of tunnel excavation [3]. Moreover, it has obvious advantages in terms of efficiency, quality, safety, and environmental protection compared with the drill-blasting method and mechanical crushing technology $[4,5]$. AWJ-assisted tunnel excavation involves drilling holes and presplitting along the working face of a tunnel to form a free surface with large fragmentation, which can reduce the explosive dosage and improve the excavation efficiency. Nevertheless, many issues with AWJ technology, such as the small effective range of fracturing, parameter mismatch, high pump pressure, and great specific energy consumption, influence the fracturing effect of AWJ. The solutions to these problems are based on in-depth studies of the failure mechanism and nozzle parameter effects for rock fragmentation.

Recently, many scholars have researched the failure mechanism and parameter effects of water jet rock-breaking. For the failure mechanism, Kovacevic et al. [6] studied the removal mechanism of material during AWJ drilling using acoustic emission (AE) sensing technology. Miranda and Quintino [7] researched the effect of material properties on 
the mechanism of the AWJ cutting of limestone by observing the microstructure of the cutting surface with a scanning electron microscope (SEM). Lu et al. [8] analyzed the damage characteristics and failure mechanism of rock impacted by a water jet based on Computed Tomography (CT) and SEM technologies. Sheng et al. [9] proposed a 3D computational fluid dynamics- (CFD-) based erosion model and analyzed the erosion patterns and breaking mechanisms of AWJ. Ren et al. [10] established the numerical model of particle water-jet impacting rock based on the Smooth Particle Hydrodynamics and Finite Elements Method (SPHFEM) coupling algorithm and explored the damage evolution and the failure effect. These studies had great achievements, but they did not analyze the internal stress field of rock, hindering the precise exploration of the failure mechanism.

With respect to parameter effect research, Oh et al. [11] studied the fracturing characteristics of hard granite with a high-pressure water jet impact experiment by measuring the various geometric dimensions of cracks. Rupam et al. [12] investigated the erosion properties of granite samples for continuous pulsating water jet and ultrasonic pulsating water jet impacts with different pressures with the evaluation of the erosion depth, width, and volume. Tripathi et al. [13] studied the effects of pulse frequency on the erosion properties of a pulsed water jet impacting sandstone, such as the erosion depth, width, and volume, using a noncontact optical profilometer. Wang et al. [14] numerically simulated the multiphase flow fields in a water jet ejector, waterpowder mixing head, and stirring tank as well as the dissolution of the two mixing methods. The abovementioned scholars mainly studied the parameter effects on rock fragmentation based on the geometric features of the broken area or cracks, ignoring the non-damage state and limiting the integrated parameter effect explorations for the rock fragmentation.

The numerical simulation of AWJ impacting rock can be used to obtain the stress distribution and record the dynamic damage state of rock to further explore the failure mechanism and parameter effects. However, it involves large deformation, a high strain rate, and other complicated issues [15]. The FEM can be used to solve various mechanical and physical problems by discretizing the continuum, as well as slicing and interpolating the finite elements. The SPH method, as a combination method of a non-mesh technique, the Lagrange method, and granular flow, can evade the precision problem brought by the large deformation of the mesh. The SPH-FEM coupling algorithm has a positive application in solving for a large impact, large deformation, and high strain rate. For example, Mueller et al. [16] and Farhoud and Ali [17] simulated the interaction of fluid and a deformable solid based on the SPH-FEM method. Moonho and Taehyo [18] and Alessandro and Khamis [19] utilized the method to carry out the three-dimensional modeling of orthogonal cutting. Using the SPH-FEM coupling method, Wang et al. [20] carried out the numerical simulation of the water inrush of a tunnel during blasting, and Li et al. [21] revealed the rock failure mechanism and the effect of confining pressure for vertical and inclined particle jet impacts. The abovementioned research provided a basis for the modeling of an AWJ impacting rock.

In this research, the numerical models of AWJ impacting rock were established using the coupled SPH-FEM algorithm, and the failure mechanism of rock was revealed by analyzing the time-history curves of the force of the rock particles at different stages and positions. At present, the effects of the parameters such as the abrasive concentration, abrasive diameter, abrasive type, stand-off distance, and jet pressure on rock fragmentation have been studied [22-24]. Nevertheless, the nozzle is the core of the AWJ system, and the structure change inside the nozzle chamber inevitably leads to the change of the flow field, which greatly affects the dynamic properties of an AWJ $[25,26]$. In particular, the diameter of the nozzle $(d)$, the convergence angle of the nozzle $(\alpha)$, and the cavity length $(L)$ have an important influence on the fluid velocity inside the nozzle [27]. Thus, in this research, the comprehensive damage factor of rock $X$ was proposed, and the effects of $d, \alpha$, and $L$ on rock fragmentation with certain technical parameters of the AWJ were studied. The results have an important theoretical significance for evaluating the rock damage under the action of an AWJ, optimizing the nozzle structure under different working conditions, improving the efficiency of an AWJassisted tunnel excavation, and promoting the application level of AWJ technology in tunnel excavation.

\section{Numerical Model}

The rock, water, and abrasives were $0.25 \mathrm{~mm}$ in diameter, and they were modeled by SPH particles. Based on the random program, some water particles were replaced by randomly distributed abrasive particles, and the concentration of abrasive particles $C$ was $20 \%$. The nozzle adopted the solid element with a dimension of $1.25 \mathrm{~mm}$, and the loading element used the shell element with a dimension of $0.25 \mathrm{~mm}$. Additionally, a vertical and downward pressure load of $150 \mathrm{MPa}$ was imposed on the upper surface of the loading element. In the actual impact test, the pressurized water and the abrasives were mixed in the nozzle. Then, the mixtures shot out the nozzle in the form of the cluster at a high speed and impacted the rock. To achieve the operability of the numerical simulation, the numerical model of the AWJ system was simplified. In the numerical simulation, the loading element was a representation of the piston forcing the water pressure inside the nozzle chamber. Driven by the water pressure, the AWJ was pushed downward, and it rushed out the nozzle. Finally, the high-pressure AWJ was generated, and it crushed the rock.

2.1. Constitutive Model of Rock. The rock was modeled by the constitutive model of Holmquist-Johnson-Cook (HJC), which comprehensively considered the influence of the high hydrostatic pressure, high strain rate, and damage, and which could reflect the nonlinear deformation of rock under AWJ impact [28]. The yield surface equation of the rock model is 


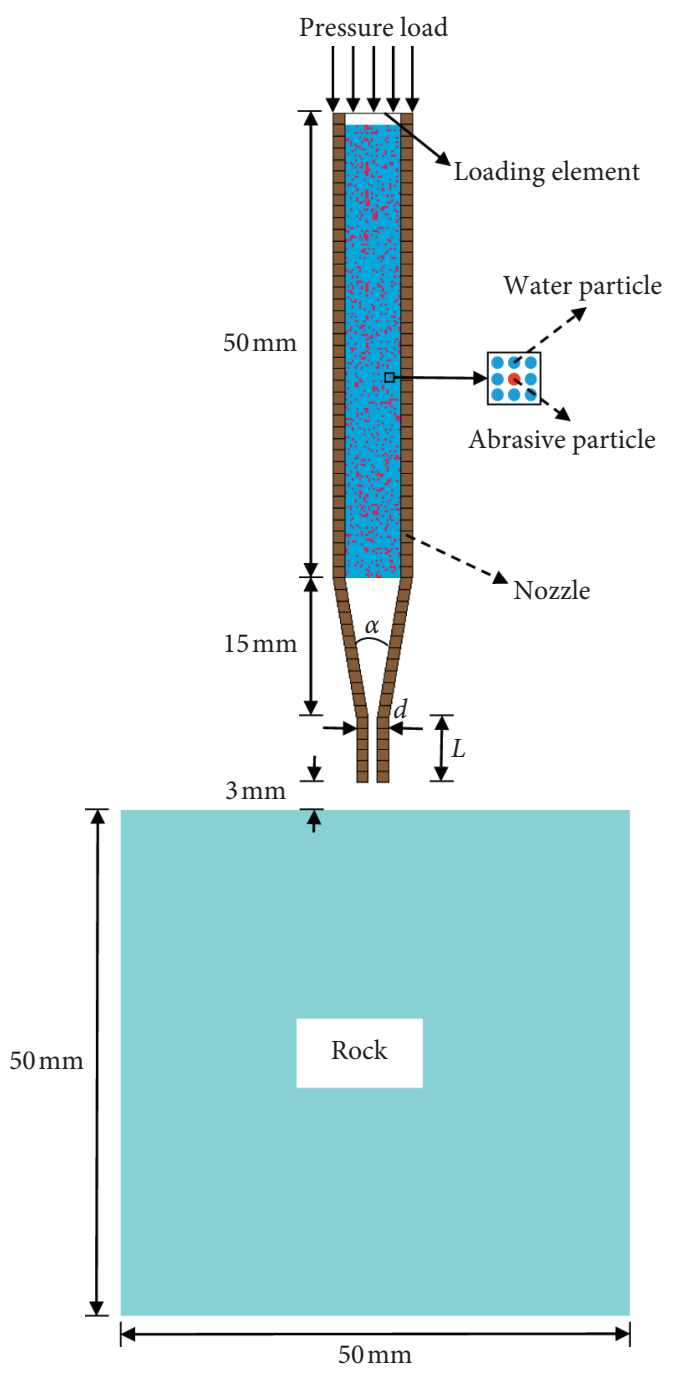

Figure 1: AWJ impacting rock model.

$$
\sigma^{*}=\left[A(1-D)+B P^{* N}\right]\left[1-C \ln \varepsilon^{*}\right]
$$

According to the HJC damage constitutive model, the damage to the rock particles $D$ was accumulated by the equivalent plastic strain and plastic volumetric strain, and the $D$ value could vary from 0 to 1 . In particular, " 0 " represented no damage, and " 1 " represented the complete failure of the rock. The $D$ value was calculated using the following equation:

$$
D=\sum \frac{\Delta \varepsilon_{p}+\Delta \mu_{p}}{\varepsilon_{p}^{f}+\mu_{p}^{f}} .
$$

In equations ( 1$)$ and $(2), \sigma^{*}=\sigma / f_{c}\left(\sigma^{*} \leqq S_{\max }\right), \sigma^{*}$ represents the normalized equivalent stress, $S_{\max }$ is the normalized maximum strength, $\sigma$ is the actual yield strength, and $f_{c}$ is the quasistatic uniaxial compressive strength. $P^{*}=P / f_{c}, \quad P^{*}$ is the normalized equivalent hydrostatic pressure, and $P$ is the hydrostatic pressure. $\varepsilon^{*}=\varepsilon / \varepsilon_{0}, \varepsilon^{*}$ is the normalized strain, $\varepsilon$ is the strain, and $\varepsilon_{0}$ is the reference strain with a value of $1.0 \mathrm{~s}^{-1}$. For the constants, $A, B$, and $C$ are the normalized cohesive coefficient, normalized pressure hardening coefficient, and strain rate coefficient, respectively. $N$ is the pressure hardening exponent. $\Delta \varepsilon_{p}$ and $\Delta \mu_{p}$ are the equivalent plastic strain and the equivalent plastic volume strain in a computational cycle, respectively. $\varepsilon_{p}^{f}$ and $\mu_{p}^{f}$ are the equivalent plastic strain and the equivalent plastic volume strain under atmospheric pressure.

Generally, the AWJ impacting brittle material mainly experienced tensile or shear failure. Therefore, the dynamic failure criterion was used to determine the failure behavior of the rock, as listed in the following equation:

$$
\sigma_{1} \geq\left[\sigma_{t}\right], \quad \tau_{\max } \geq[\tau]
$$

In the equation, $\sigma_{1}, \tau_{\max },\left(\sigma_{t}\right)$, and $(\tau)$ are the maximum principal stress of rock, the maximum shear stress of rock, the dynamic tensile strength of rock, and the dynamic shear strength of rock, respectively.

The rock utilized the sandstone, and the constitutive parameters for the sandstone are displayed in Table 1. The parameter values of the density of rock $\rho_{0}$, the quasistatic compression strength, the quasistatic tensile strength, and the quasistatic shear strength were determined with the measuring test of the density, the compression test, the tensile test, and the shear test. Under dynamic loading, there was an obvious strain rate effect of the strength of rock increasing with an increase of the strain rate, but the strength did not increase infinitely, and it had an extreme value [29]. In addition, the dynamic strength of the rock was approximately proportional to the quasistatic strength. Therefore, on the basis of the generally linear relationship between the dynamic strength and the quasistatic strength of the rock, the parameter values of the dynamic compressive strength of the rock $\left(\sigma_{c}\right)$, the dynamic tensile strength $\left(\sigma_{t}\right)$, and the dynamic shear strength $(\tau)$ under AWJ impact were calculated. For the parameters $A, B, C, N$, and $S_{\max }$, in this research, the preliminary value ranges were first obtained based on relevant references; then the experiment and numerical simulation results of the AWJ impacting rock were compared for the different parameter combinations, and finally, the optimal parameter combination was determined.

2.2. Constitutive Model of AWJ. The AWJ model consisted of water and abrasives, in which the constitutive model of NULL was used for the water, as given in the state equation of Grüneisen, as shown in the following equation [30]:

$$
P=\frac{\rho_{w} C^{2} \mu\left[1+\left(1-\left(\gamma_{0} / 2\right)\right) \mu-(a / 2) \mu^{2}\right]}{\left[1-\left(S_{1}-1\right) \mu-S_{2}\left(\mu^{2} /(\mu+1)\right)-S_{3}\left(\mu^{3} /(\mu+1)^{2}\right)\right]^{2}}+\left(\gamma_{0}+a \mu\right) E .
$$

In equation (4), $\rho_{w}$ is the density of water at the nonstress or nondeformed state, which could be obtained with the measuring test of density. $C$ is the intercept of the curve between the shock wave velocity $\left(v_{s}\right)$ and the particle velocity of water $\left(v_{p}\right)$, and $S_{1}, S_{2}$, and $S_{3}$ are the slopes of the $v_{s^{-}} v_{p}$ curves. $\mu=\rho / \rho_{w}, \rho$ is the current density, and $\mu$ is the 
TABLE 1: Constitutive parameters for the sandstone.

\begin{tabular}{lcccccccc}
\hline$\rho_{0}\left(\mathrm{~g} \bullet \mathrm{cm}^{-3}\right)$ & $f_{\mathrm{c}}(\mathrm{MPa})$ & $A$ & $B$ & $C$ & $N$ & $S_{\max }$ & $\left(\sigma_{t}\right)(\mathrm{MPa})$ & $(\tau)(\mathrm{MPa})$ \\
\hline 2.44 & 68 & 0.79 & 1.80 & 0.007 & 0.61 & 7 & 12 & 40 \\
\hline
\end{tabular}

volumetric parameter. $\gamma_{0}$ is the unitless Grüneisen gamma, and $\alpha$ is the first-order volume correction to $\gamma_{0}$. Parameter values of $C, \mu, S_{1}, S_{2}, S_{3}$, and $\gamma_{0}$ could be obtained by consulting relevant references. The constitutive parameters for water are listed in Table 2 .

The abrasives utilized the garnet, and they were also simulated by the HJC constitutive model. The constitutive parameters for the abrasives are listed in Table 3. $\rho_{A}$ is the density of the garnet. Its value was obtained with the measuring test of density. The constitutive model of the abrasive was the same as the rock model, so the parameter values of $A, B, C, N$, and $S_{\max }$ were determined with the same method as that for the parameters in Table 1.

2.3. Constitutive Model of Nozzle and Loading Element. In the actual experiment, the deformation of the nozzle structure was very small, and the deformation could be negligible, so both the nozzle and the loading element utilized the rigid element, and they were modeled based on the RIGID constitutive model [31, 32]. The main parameters are presented in Table 4.

\section{Verification}

AWJ impacting sandstone was used in an experiment under the same working condition to verify the reliability of the numerical simulation. In the numerical simulation and the experiment, the diameter of the nozzle $(d)$, the convergence angle of the nozzle $(\alpha)$, the cavity length $(L)$, the stand-off distance $(H)$, the impact time $(t)$, the water pressure $(P)$, and the abrasive concentration $(C)$ were $1 \mathrm{~mm}, 20^{\circ}, 7 \mathrm{~mm}, 3 \mathrm{~mm}$, 30 s, $150 \mathrm{MPa}$, and $20 \%$, respectively. The AWJ apparatus was provided by Shanghai Jinjian Waterjet Manufacturing Co., Ltd. (Figure 2(a)). By the comparative analysis in Figure 2(b) and Figure 2(c), some common macrofailure characteristics of the rock in the numerical simulation and the experiment could be found. Additionally, the craters with 15-20 times the jet diameter were generated in the impact center of the AWJ. The cracks were initiated below the crater, and they propagated along the radial direction (the impact direction of the AWJ) and the axial direction (the diameter direction of the AWJ).

Furthermore, in this research, a CT scan of the rock was conducted after the AWJ impact to verify the numerical model. Figure 3 shows the 16-slice spiral Siemens SOMATOM scope CT scanner and the scan results. There was a great difference in gray scale between the crack region and the noncrack region. First, the image processing and the image binarization method were utilized to extract the crack regions of the numerical simulation image and the CT slice and to convert the color image into a black-and-white image. To ensure that the gray scale value was positively correlated with the rock damage, the gray scale values of the white pixel and black pixel were inverted, so the gray scale value of the black pixel was set to 255 , and the gray scale value of the white pixel was set to 0 . Then, the numerical simulation image and the CT slice were segmented into five regions along the axial and radial directions. The dimensions of each region were $188 \mathrm{px} \times 188 \mathrm{px}$, with a total of 35344 pixels. Finally, the average gray scale value of all pixels in each region was calculated to characterize the damage of the region.

Figure 4 presents the results after image processing and image segmentation. By calculating the average gray scale values of the five regions along the axial and radial directions, the evolution trend of the average gray scale values from the impact center to the surrounding area was obtained, as demonstrated in Figure 5. It could be recognized that the gray scale values of regions III'-1' and III" $-1^{\prime \prime}$ were the largest, and the average gray scale values of the five regions along the axial and radial directions showed a decreasing trend. The regions $\mathrm{III}^{\prime}-1^{\prime}$ and $\mathrm{III}^{\prime \prime}-1^{\prime \prime}$ were close to the liquid-solid contact zone, and they had the largest impact load, so the rock damage was the largest. Due to the stress attenuation and the damping effect of the fluid, as radial and axial distances increased, the energy density of the AWJ and the rock damage decreased.

According to the abovementioned analysis, the numerical simulation and the experimental results were consistent, which reflected the numerical simulation reliability and provided a way to further explore the failure mechanism of the rock under the AWJ impact and the nozzle parameter effects on the rock fragmentation.

\section{Discussion and Analysis}

\subsection{Failure Mechanism of Rock Impacted by AWJ}

4.1.1. Formation Mechanism of the Crater. Under the abovementioned simulation conditions $(d=1 \mathrm{~mm}$, $\alpha=20^{\circ}, L=7 \mathrm{~mm}, H=3 \mathrm{~mm}, t=30 \mathrm{~s}, P=150 \mathrm{MPa}$, and $C=20 \%)$, the AWJ was accelerated in the nozzle, and it reached the rock surface at $t=232 \mu \mathrm{s}$, generating a strong impact in the liquid-solid contact zone. The $D$-values of the typical particles P1, P2, P3, and P4 in the liquid-solid contact zone reached 1 at $t=234 \mu \mathrm{s}$, at which time the four particles were destroyed, as shown in Figure 6. By extracting the stress values of the four particles, the stress variation curves versus time were obtained, as demonstrated in Figure 7. The peak compressive stresses and the peak shear stresses of the four particles all exceeded $\left(\sigma_{c}\right)$ with the value of $68 \mathrm{MPa}$ and $(\tau)$ with the value of $40 \mathrm{MPa}$ at approximately $t=234 \mu \mathrm{s}$, at which time the peak tensile stresses did not yet exceed $\left(\sigma_{t}\right)$ with the value of $12 \mathrm{MPa}$. According to the abovementioned analysis, it could be concluded that the particles in the liquid-solid contact zone mainly failed with the combined action of the compression stress and the shear stress. 
TABLE 2: Constitutive parameters for the water.

\begin{tabular}{lccccccc}
\hline$\rho_{w}\left(\mathrm{~g} \cdot \mathrm{cm}^{-3}\right)$ & $C\left(\mathrm{~cm} \cdot \mu \mathrm{s}^{-1}\right)$ & $\mu$ & $S_{1}$ & $S_{2}$ & $S_{3}$ & $\gamma_{0}$ & $\alpha$ \\
\hline 1 & 0.148 & $1 \times 10^{-8}$ & 2.56 & -1.986 & 0.2286 & 0.5 & 1.397 \\
\hline
\end{tabular}

TABLE 3: Mechanical parameters for the abrasives.

\begin{tabular}{lcccrr}
\hline$\rho_{A}\left(\mathrm{~g} \cdot \mathrm{cm}^{-3}\right)$ & $A$ & $B$ & $C$ & $N$ & $S_{\max }$ \\
\hline 3.2 & 0.79 & 1.8 & 0.007 & 0.61 & 11 \\
\hline
\end{tabular}

TABLe 4: Main parameters of nozzle and loading element.

\begin{tabular}{lcc}
\hline Mass density & Modulus of elasticity & Poisson's ratio \\
\hline $7.86 \mathrm{~g} \cdot \mathrm{cm}^{-3}$ & $2.1 \times 10^{5} \mathrm{MPa}$ & 0.3 \\
\hline
\end{tabular}

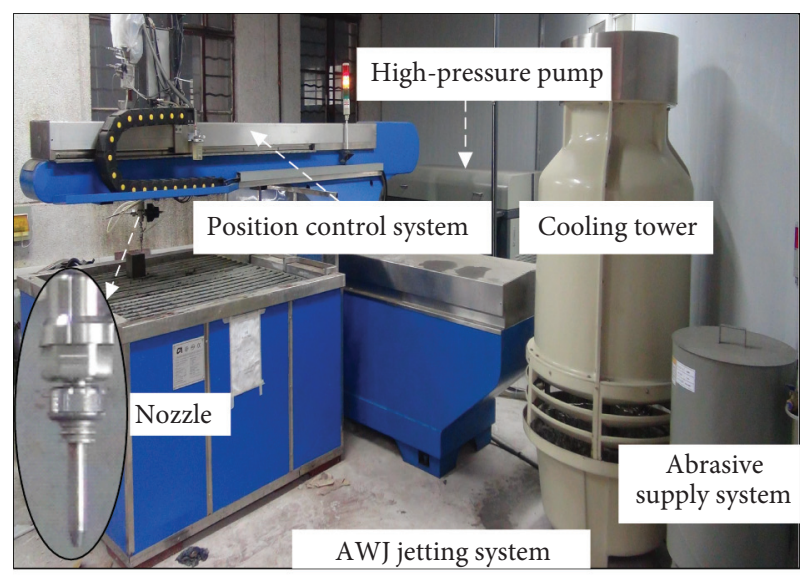

(a)

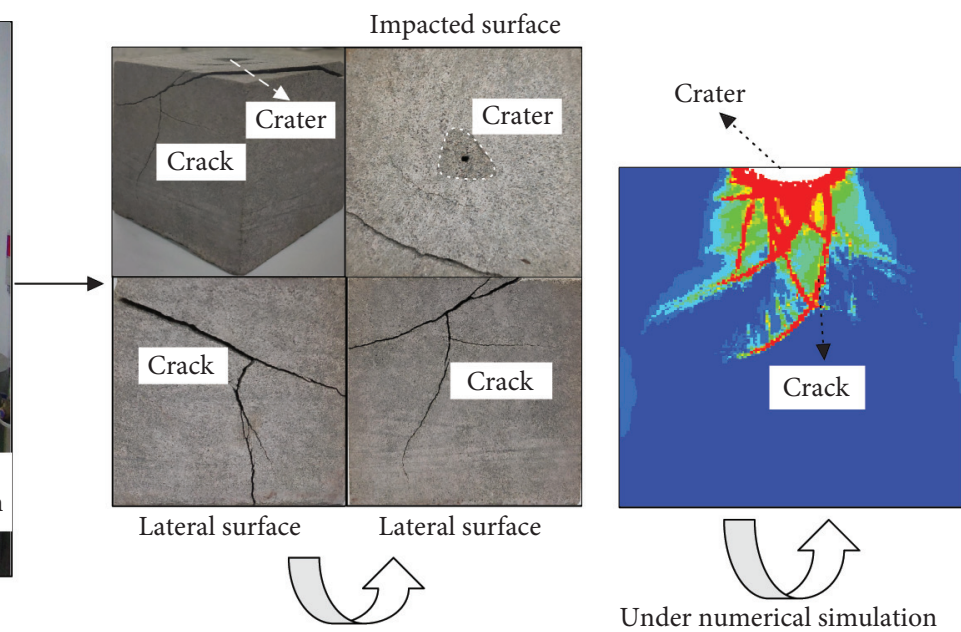

After AWJ impact

(b) (c)

FIgURE 2: Experimental devices of AWJ impacting rock and the results.

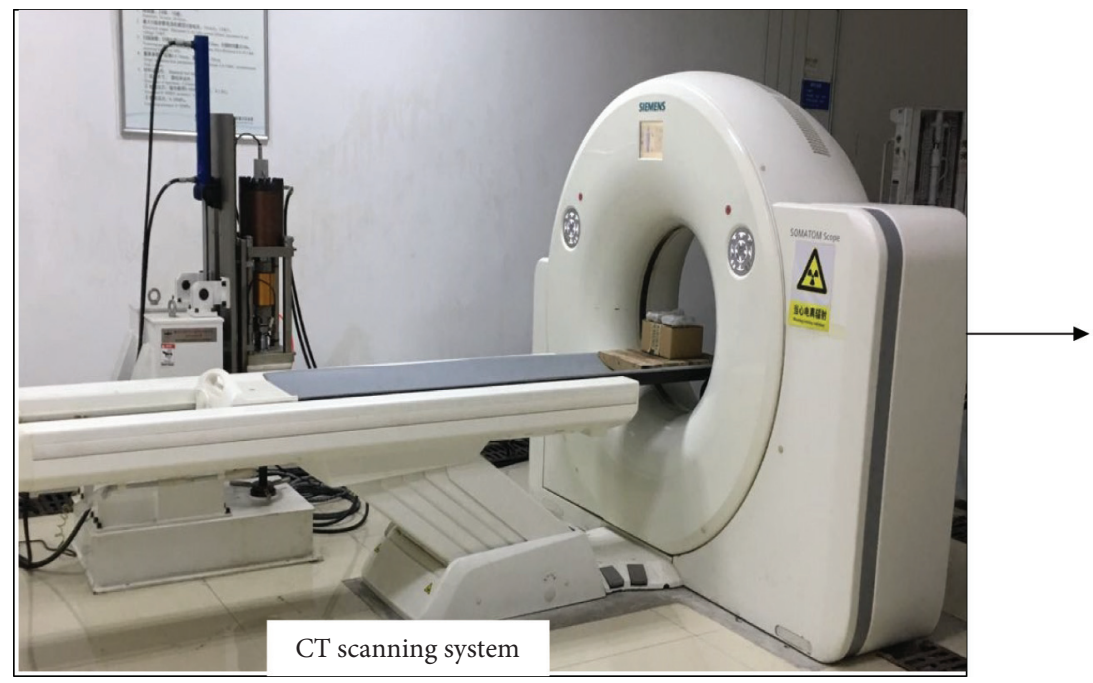

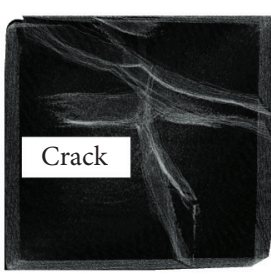

$3 \mathrm{D}$ reconstruction

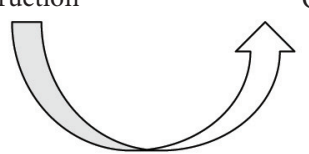

CT scan results of rock after AWJ impact

FIGURE 3: CT scanning system and the results. 

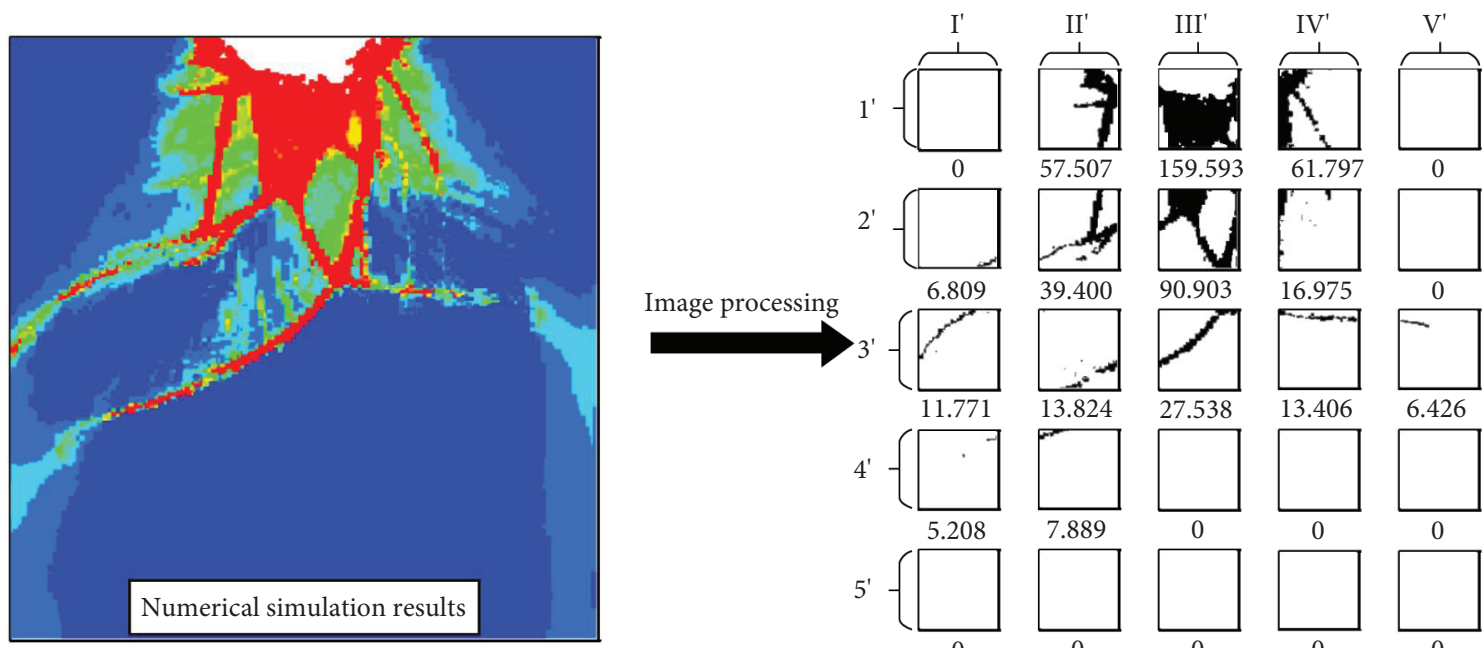

61.797
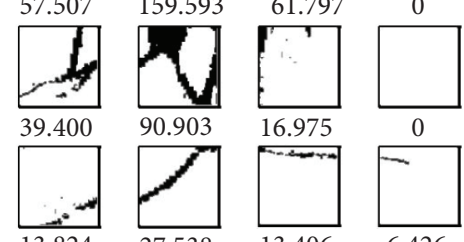

0

$4^{\prime}$

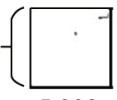

13.824
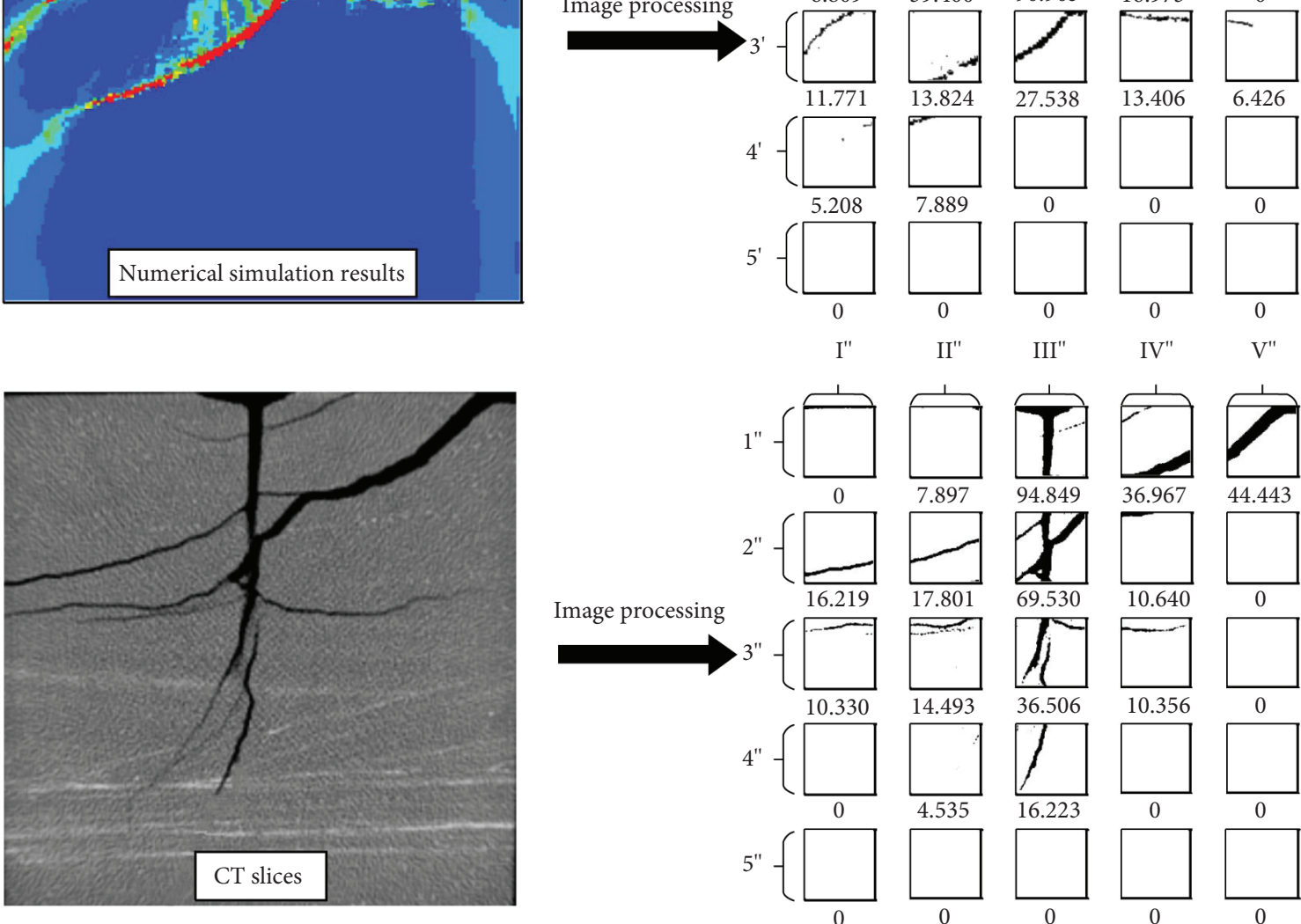

III"

IV"

$\mathrm{V}^{\prime \prime}$
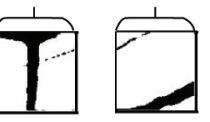

36.967
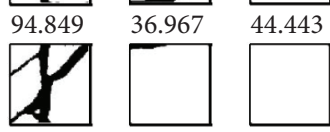

$69.530 \quad 10.640$

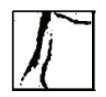

$36.506 \quad 10.356$
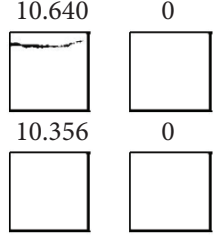

FIGURE 4: Image processing results of AWJ impacting rock.

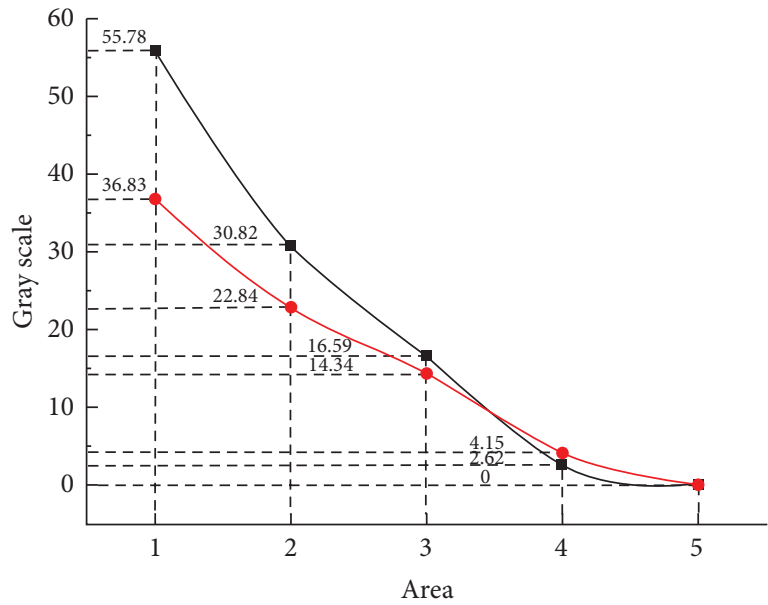

$\rightarrow$ Numerical simulation

$\rightarrow$ CT experiment

(a)

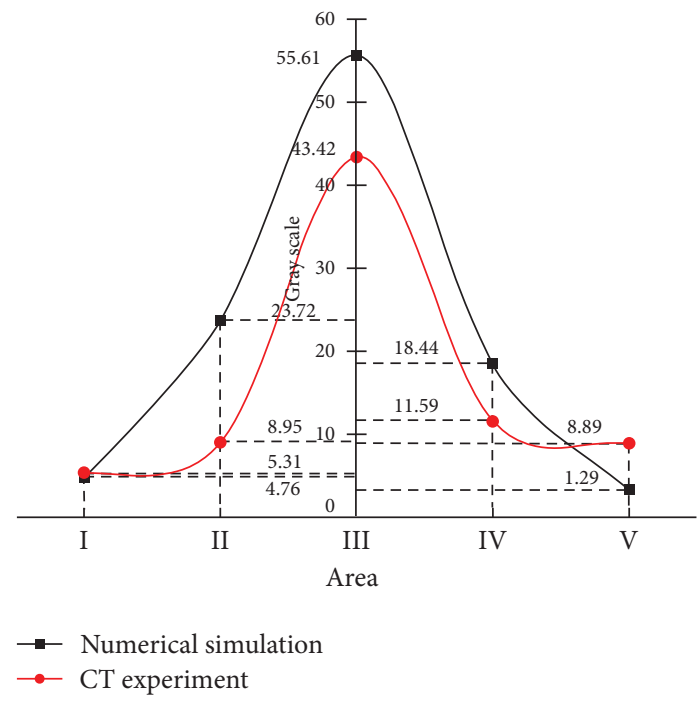

(b)

FIGURE 5: Evolution curve of average gray scale of rock impacted by AWJ. (a) Axial direction. (b) Radial direction. 


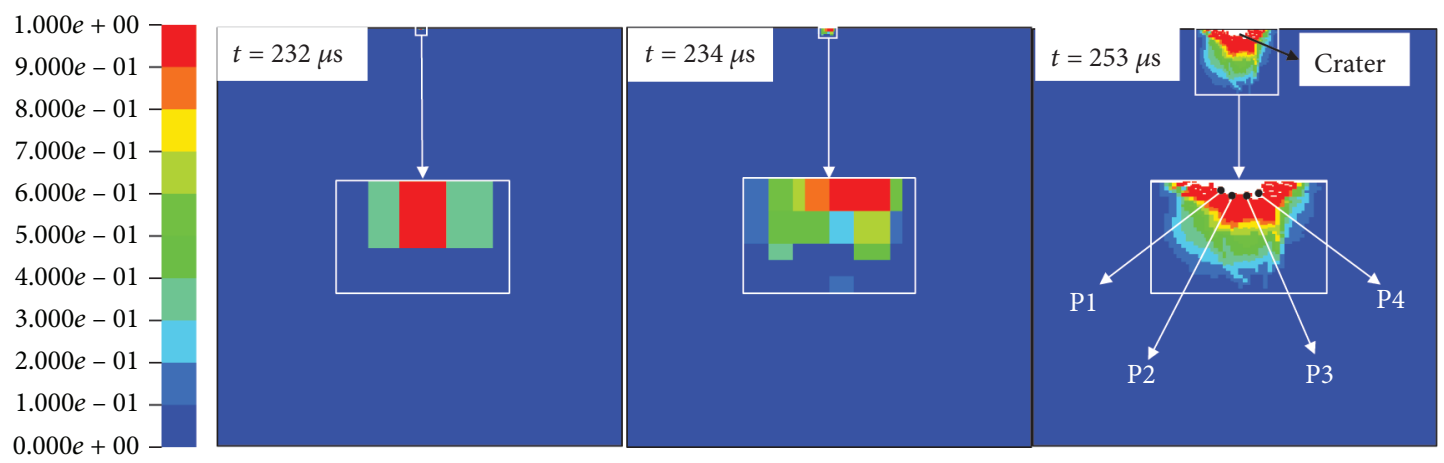

(a)
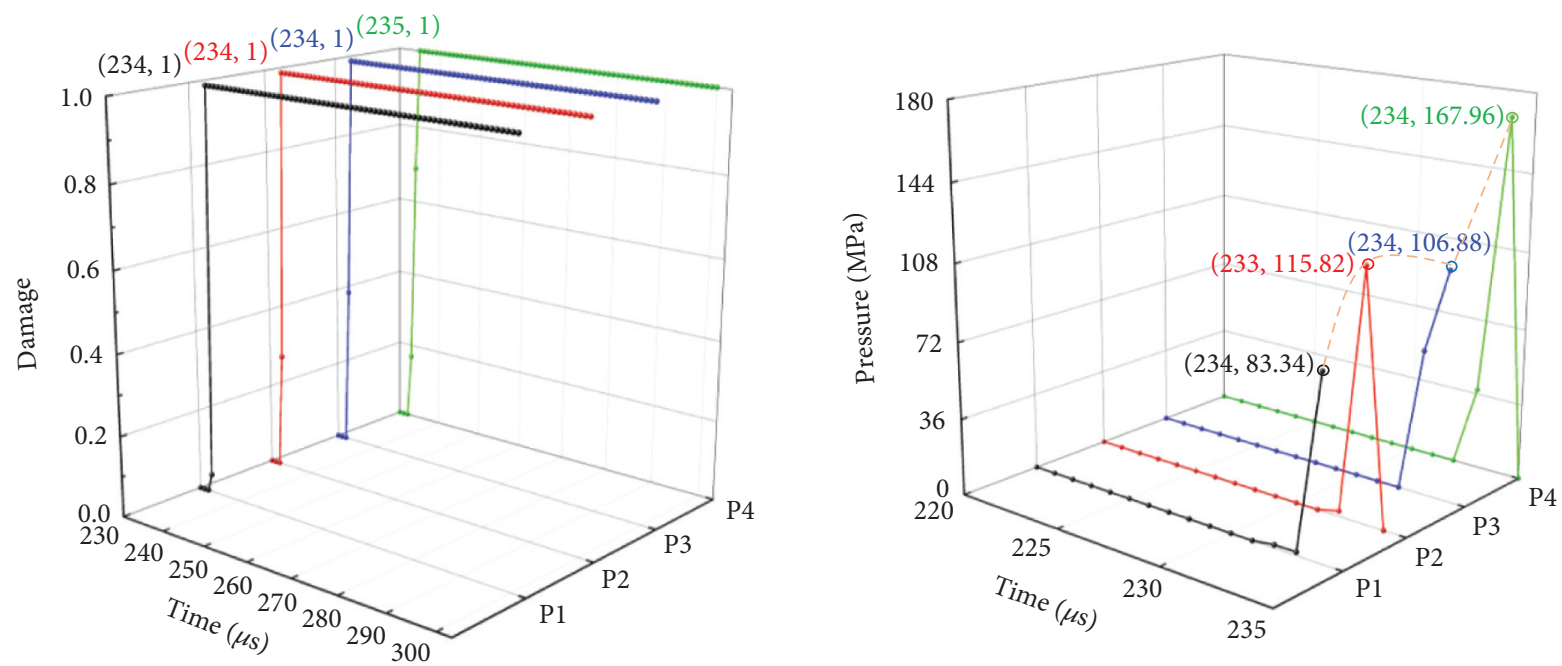

(b)

Figure 6: The formation of the crater. (a) The formation process of the crater. (b) Damage and pressure of particles in the liquid-solid contact area.

The abrasive particles were completely accelerated by the drag force of the high-speed water beam, which induced intense compression when the AWJ contacted the rock, the peak pressures of the three particles $\left(P_{\max }\right)$ in the liquid-solid contact center were at a high level, and $P_{\max } \in(83.34 \mathrm{MPa}, 167.96 \mathrm{MPa})$. Also, the abrasive particles had sharp angularity, and the AWJ also aroused the cutting effect. Thus, the strong impact of the AWJ evoked the large compressive stress and a high-density shear stress field. Under the action of the compressive stress and the shear stress, a plastic deformation zone formed in the liquid-solid contact zone. The plastic deformation zone was gradually enlarged with the impact of the AWJ, and a crater was generated.

4.1.2. Formation and Expansion Mechanism of Cracks. Under the impact of the AWJ, the damage to partial particles at the bottom of the crater sharply increased, and these particles were completely destroyed at a certain time. Crack I was generated at $t=254 \mu \mathrm{s}$. Subsequently, crack II and crack III were produced simultaneously at $t=270 \mu \mathrm{s}$, and crack IV was initiated at $t=286 \mu \mathrm{s}$. With the sustained action of the
AWJ, the four cracks constantly expanded, intersected, and extended toward the boundary of the rock, as demonstrated in Figure 8.

To reveal the formation and expansion mechanisms of the cracks in the rock, the stresses of typical particles in the crack formation zone and the expansion zone were extracted. The stress variation curves of these particles with time are shown in Figure 9. According to Figure 9(a), before the compressive stresses exceeded $\left(\sigma_{c}\right)$, the tensile stresses and the shear stresses of the particles P5, P6, P7, and P8 in the crack formation zone first reached $\left(\sigma_{t}\right)$ and $(\tau)$, and the four particles were destroyed. As shown in Figure 9(b), before the particles $\mathrm{P} 9, \mathrm{P} 10, \mathrm{P} 11$, and $\mathrm{P} 12$ in the crack expansion zone were destroyed, the tensile stresses of the four particles first exceeded $\left(\sigma_{t}\right)$, yet the compressive stresses and shear stresses did not reach $\left(\sigma_{c}\right)$ and $(\tau)$. It could be concluded that the particles in the crack formation zone mainly experienced tensile and shear failure, and the particles in the expansion zone mainly failed with the tensile stress.

After the crater was formed, a series of cracks were generated below the crater, and the cracks propagated with the sustained action of the AWJ. With the stress analyses of 


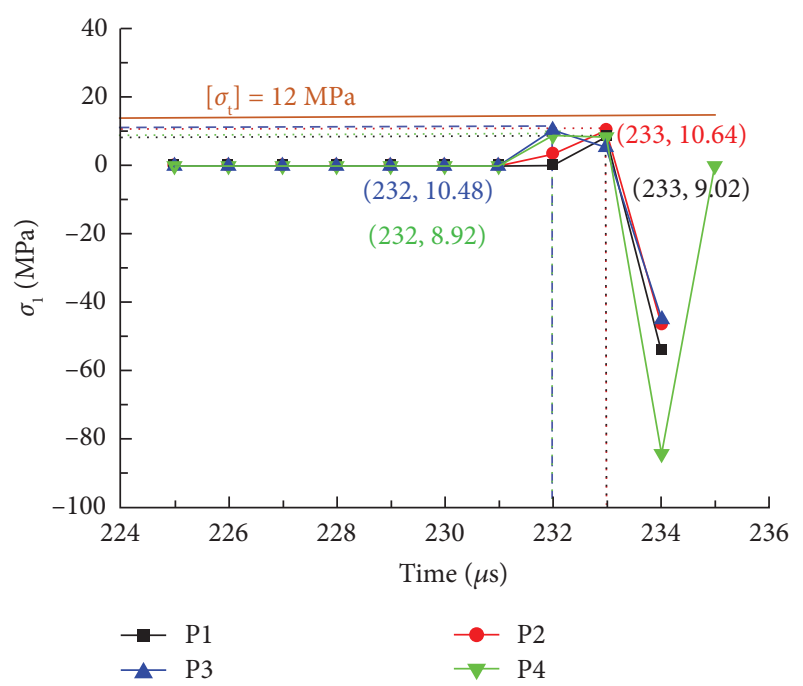

(a)

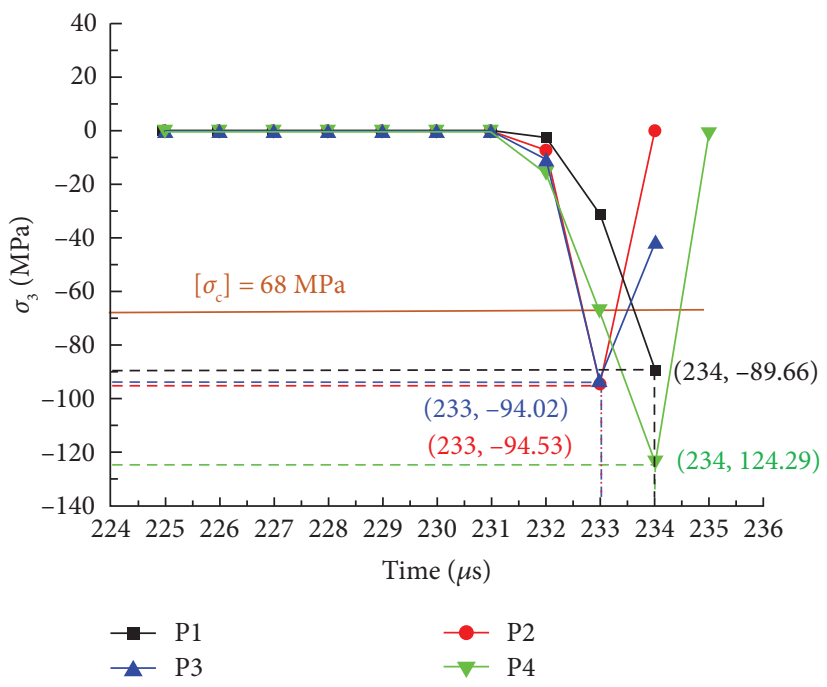

(b)

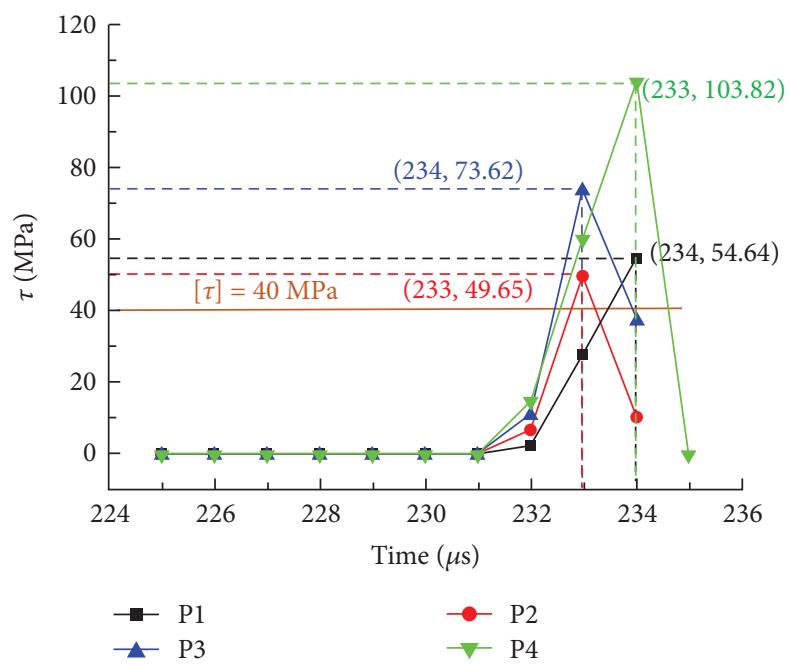

(c)

FIGURE 7: Stress variation curves of four particles in the liquid-solid contact area versus time.

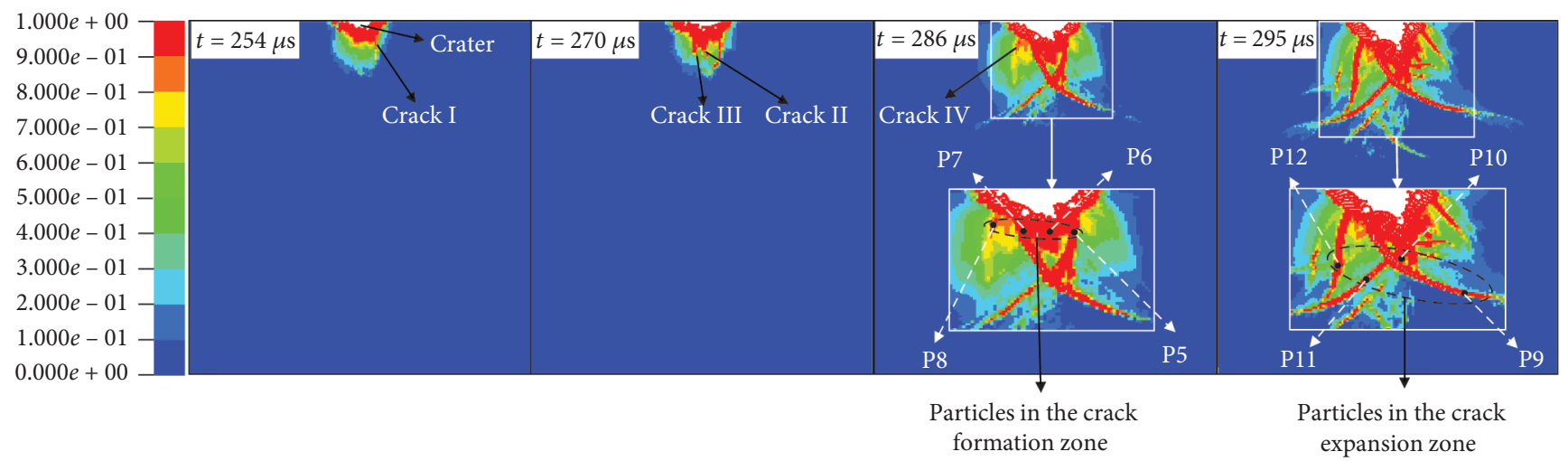

FIGURE 8: The formation and expansion process of cracks. 

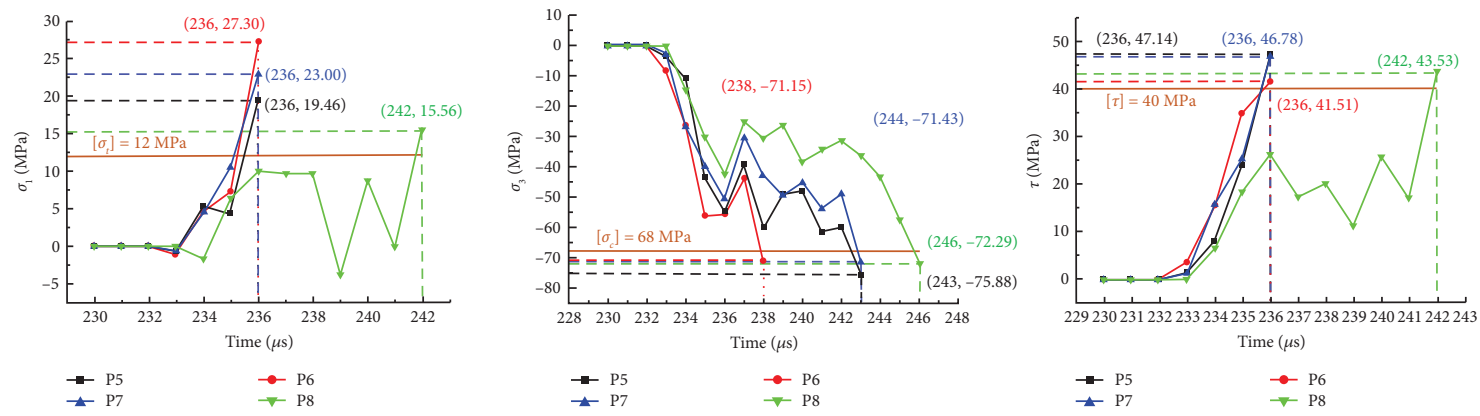

(a)
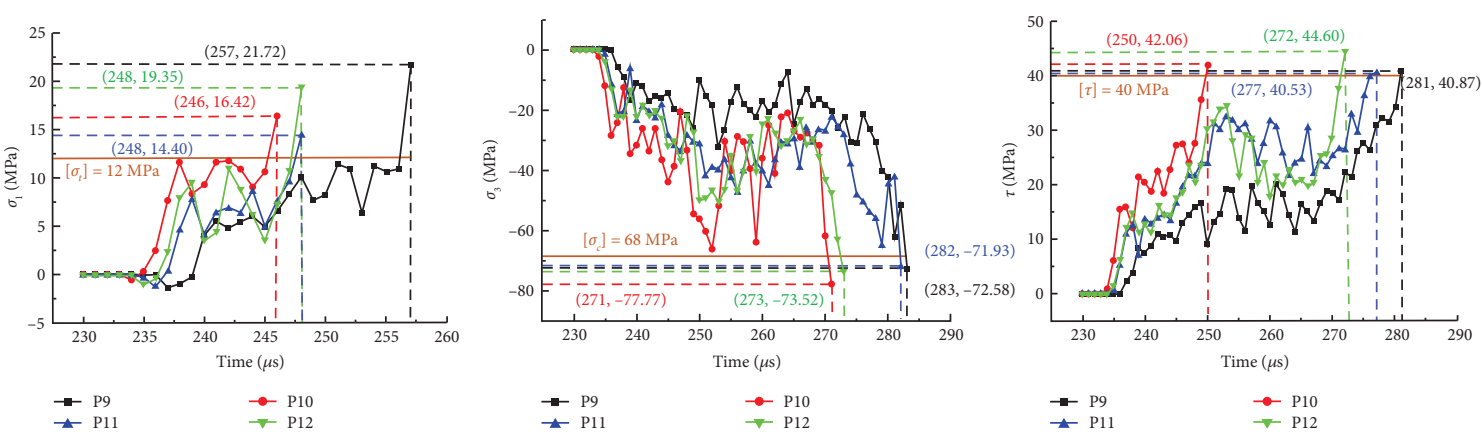

(b)

FIGURE 9: Stress variation curves of rock particles versus time. (a) Crack formation zone. (b) Crack expansion zone.

the typical rock particles in the crack formation zone and the expansion zone, the cracks in the rock were mainly produced by the tensile stress and the shear stress, and the expansions of the cracks were mainly generated by the tensile stress.

4.2. Influence Analyses of Nozzle Parameters. To study the effects of the nozzle parameters on the rock fragmentation under the AWJ impact, it was necessary to explore the rock fragmentation state with different nozzle parameters.
Nevertheless, it was difficult to reflect the whole fragmentation state of the rock simply using the geometric features of the damaged area. Therefore, $X$ was defined to quantify rock fragmentation. First, the numerical simulation image was processed based on image processing and image segment. Then, the rock damage was divided into 10 grades, and the color gamut of the corresponding damage levels I to X was extracted, as displayed in Figure 10. Finally, the $X$-value was calculated with the following equation:

$$
X=\frac{0 \times S_{1}+0.1 S_{2}+0.2 S_{3}+0.3 S_{4}+0.4 S_{5}+0.5 S_{6}+0.6 S_{7}+0.7 S_{8}+0.8 S_{9}+0.9 S_{10}}{S} .
$$

In the equation, $S_{1}-S_{10}$ represent the damage areas of the damaged images corresponding to damage levels I to $\mathrm{X}$, and $S$ is the total area of the damaged image. The value calculations of $S$, $S_{1}-S_{10}$ were based on the pixel extraction method. By giving the value of 1 to all pixels in each damaged image, the value of $S$ was equal to the number of all pixels in each damaged image. For the value calculations of parameters $S_{1}-S_{10}$, the pixels in the background area were given the value of 0 , and the pixels in the damaged area were given the value of 1 .

The orthogonal design is a method based on the principle of mathematical statistics and orthogonality. This method was used to conduct the comprehensive selection of representative points in the orthogonal array. These representative points had the advantages of uniform discursiveness and comparability. Thus, the method could reflect the objective law, and it had higher calculation efficiency. In this research, the orthogonal design was carried out in order to analyze the influence of the nozzle parameters on the rock fragmentation. The $d, \alpha$, and $L$ were selected as the studied factors, and each factor had four levels, as shown in Table 5. According to the division principle of the orthogonal array, sixteen combination schemes were obtained. For different combination schemes, damaged images of the rock at $t=300 \mu$ s were extracted, and the $X$-values were calculated, as listed in Table 6.

In this research, the range analysis was carried out in order to judge whether the influence of the nozzle parameters on the rock fragmentation was significant. The range of each factor $R$ was calculated using the following equation [33]:

$$
R=\max \left\{\overline{K_{i}}\right\}-\min \left\{\overline{K_{i}}\right\}
$$

In the formula, $i$ is the level number, and $\overline{K_{i}}$ is the average value of all $X$-values at the level of $i$. 


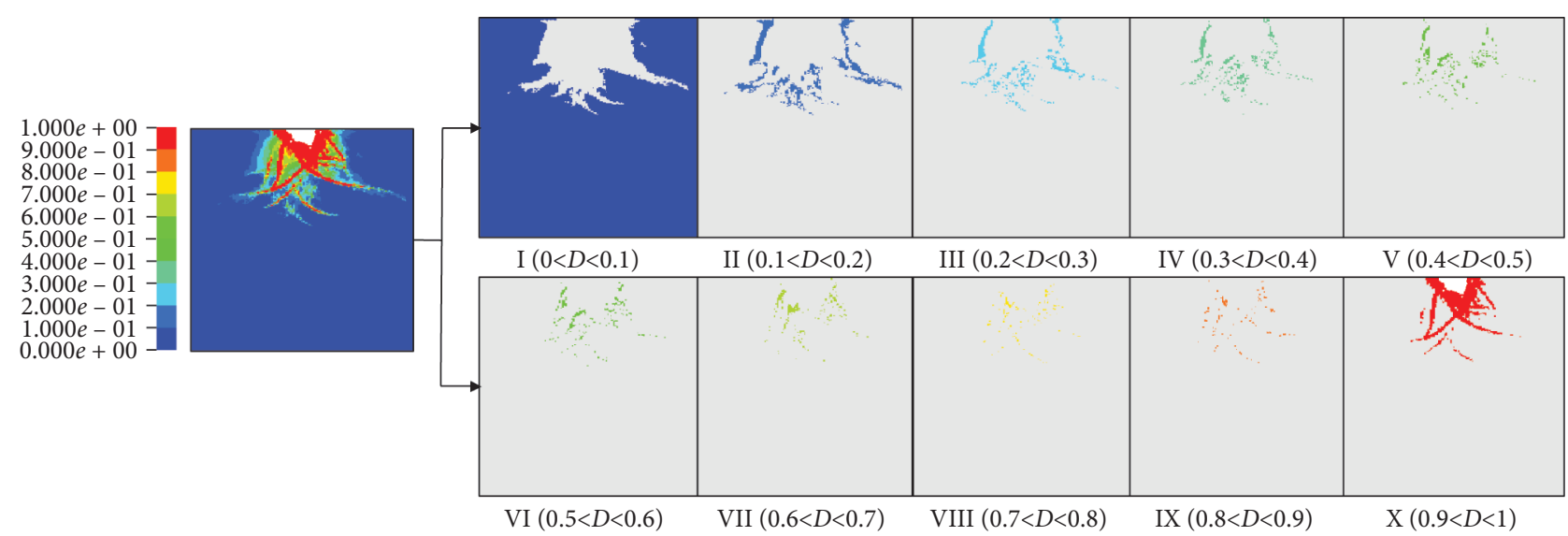

Figure 10: Damaged images corresponding to damage level I to X.

TABLE 5: Factor and level.

\begin{tabular}{lcccc}
\hline Factor & & & Level & \\
& 1 & 2 & 3 & 4 \\
\hline$d(\mathrm{~mm})$ & 1 & 2 & 40 & 4 \\
$\alpha\left({ }^{\circ}\right)$ & 20 & 30 & 9 & 50 \\
$L(\mathrm{~mm})$ & 7 & 8 & 10 \\
\hline
\end{tabular}

TABLE 6: Analyses of variance and range for nozzle parameters.

\begin{tabular}{|c|c|c|c|c|}
\hline Index & $d$ & $\alpha$ & $L$ & $X$ \\
\hline (1) & $1 \mathrm{~mm}$ & $20^{\circ}$ & 7 & 0.0818 \\
\hline (2) & $1 \mathrm{~mm}$ & $30^{\circ}$ & 8 & 0.0836 \\
\hline (3) & $1 \mathrm{~mm}$ & $40^{\circ}$ & 9 & 0.1306 \\
\hline (4) & $1 \mathrm{~mm}$ & $50^{\circ}$ & 10 & 0.1336 \\
\hline (5) & $2 \mathrm{~mm}$ & $20^{\circ}$ & 8 & 0.0308 \\
\hline (6) & $2 \mathrm{~mm}$ & $30^{\circ}$ & 9 & 0.1062 \\
\hline (7) & $2 \mathrm{~mm}$ & $40^{\circ}$ & 10 & 0.1514 \\
\hline (8) & $2 \mathrm{~mm}$ & $50^{\circ}$ & 7 & 0.1868 \\
\hline (9) & $3 \mathrm{~mm}$ & $20^{\circ}$ & 9 & 0.0665 \\
\hline (10) & $3 \mathrm{~mm}$ & $30^{\circ}$ & 10 & 0.12 \\
\hline (11) & $3 \mathrm{~mm}$ & $40^{\circ}$ & 7 & 0.1393 \\
\hline (12) & $3 \mathrm{~mm}$ & $50^{\circ}$ & 8 & 0.2208 \\
\hline (13) & $4 \mathrm{~mm}$ & $20^{\circ}$ & 10 & 0.0741 \\
\hline (14) & $4 \mathrm{~mm}$ & $30^{\circ}$ & 7 & 0.1175 \\
\hline (15) & $4 \mathrm{~mm}$ & $40^{\circ}$ & 8 & 0.1651 \\
\hline (16) & $4 \mathrm{~mm}$ & $50^{\circ}$ & 9 & 0.1866 \\
\hline$R$ & 0.0293 & 0.1187 & 0.0116 & \\
\hline$S_{E}$ & 0.00423 & & & \\
\hline$f_{E}$ & 6 & & & \\
\hline$f_{j}$ & 3 & 3 & 3 & \\
\hline$F_{j}$ & 1.135 & 14.837 & 0.137 & \\
\hline & $F_{0.1}(3,6)=3.29$ & $F_{0.01}(3,6)=9.15$ & $F_{0.1}(3,6)=3.29$ & \\
\hline
\end{tabular}

The greater the value of $R$, the larger the influence of the nozzle parameter on the $X$-value, which reflected the greater influence of the factor on the rock fragmentation. According to the result analysis shown in Table 6, the value of $R$ in factor $\alpha$ reached the maximum of 0.1187 , the value of $R$ in factor $d$ was 0.0293 , and the value of $R$ in factor $L$ was the minimum of 0.0116 . It could be recognized that factor $\alpha$ had a significant influence on the $X$ value, the influence of factor $d$ was the second most significant, and the influence of factor $L$ had the smallest significance.

Additionally, a variance analysis could balance the difference between the results caused by the changes of the factor and the level as well as the error fluctuation, so a variance analysis was also conducted. The larger the ratio of the sum of the squares of the deviations between and within groups to the degree of freedom $F_{j}$ to $F\left(f_{j}, f_{e}\right)$, the greater the influence of the factor on the rock fragmentation is [34]: 


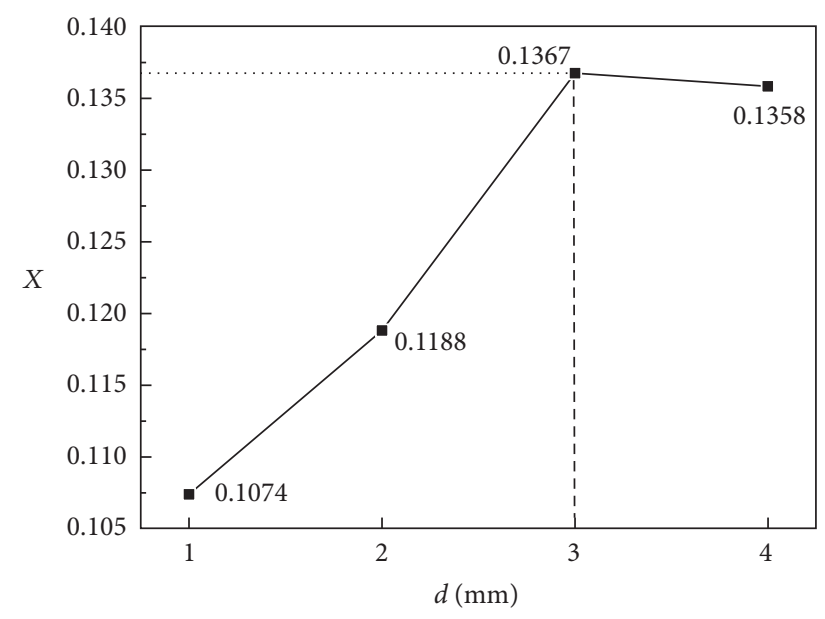

(a)

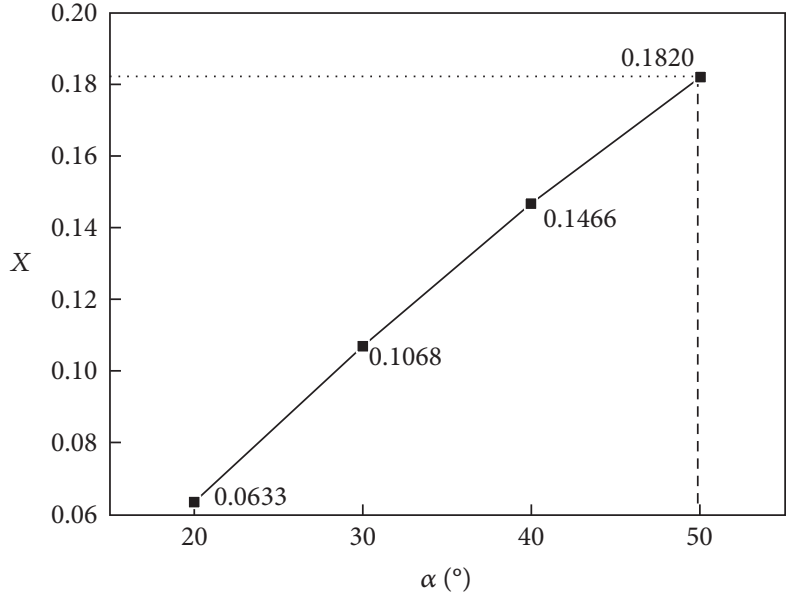

(b)

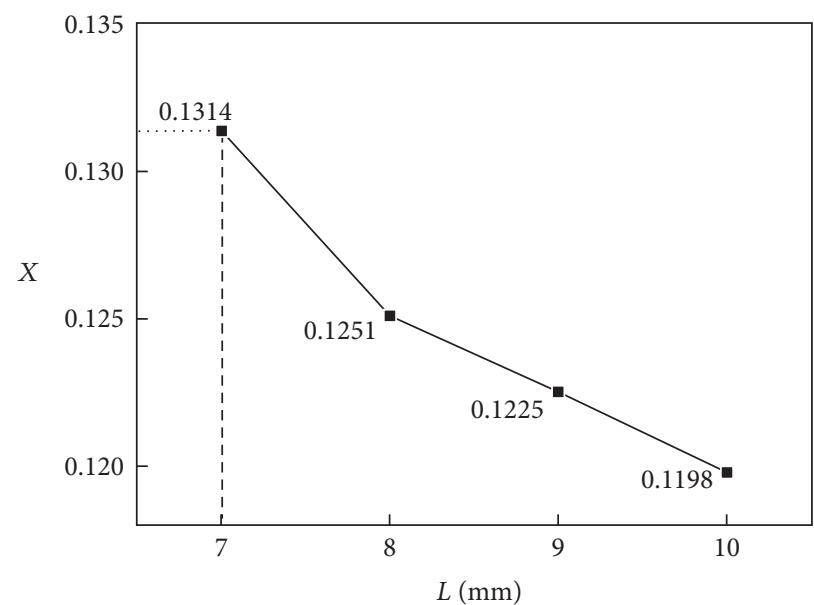

(c)

Figure 11: The change curve of the $X$-value under the single parameter.

$$
F_{j}=\frac{\left[1 / k \sum_{i=1}^{m}\left(\sum_{j=1}^{k} Y_{i j}\right)^{2}-1 / n\left(\sum_{i=1}^{m} \sum_{j=1}^{k} Y_{i j}\right)^{2}\right] f_{E}}{\left[\sum_{i=1}^{m} \sum_{j=1}^{k} Y_{i j}^{2}-1 / n\left(\sum_{i=1}^{m} \sum_{j=1}^{k} Y_{i j}\right)^{2}-\sum_{j=1}^{k} S_{j}\right] f_{j}} .
$$

In the formula, $m$ is the level number. $k$ is the number of factors. $n$ is the total number of tests. $\mathrm{Y}_{i j}$ is the $X$-value of factor $j$ at level i. $f_{j}$ is the degree of freedom of each factor. $f_{E}=f_{T}-\sum_{j=1}^{k} f_{j}, f_{T}$ is the total degree of freedom of the test, and $f_{E}$ is the degree of freedom of the test error.

According to Table 6, it could be found that the ratio $F_{j}$ to $F\left(f_{j}, f_{e}\right)$ in the factor $\alpha$ had the maximum value with the confidence level of $P=99 \%$. The parameter $\alpha$ had the greatest influence on the rock fragmentation with the AWJ impact, followed by $d$ and $L$, which was consistent with the range analysis.

For the single nozzle parameter, as the value of the parameter varied, the $X$-value of the rock changed. Therefore, a further analysis was carried out to study the influence of the single parameter on the rock fragmentation. Figure 11 shows the variation curve of the $X$-values for the parameters $d, \alpha$, and $L$.

For the parameter $d$, as $d$ increased from $1 \mathrm{~mm}$ to $3 \mathrm{~mm}$, the $X$-value linearly increased. However, the $X$-value gently decreased with an increase from $3 \mathrm{~mm}$ to $4 \mathrm{~mm}$ in the $d$ value. For the parameter $\alpha$, when $\alpha$ increased from $20^{\circ}$ to $50^{\circ}$, the $X$-value linearly increased. The flow rate and the momentum of the AWJ had a significant influence on the rock fragmentation. The momentum-transfer capability of the AWJ and the velocity of the abrasives increased with the increase of $d$ and $\alpha$. In a certain range of $d$ and $\alpha$ values, the value change had a significant influence on the rock fragmentation. With an increase of $d$ and $\alpha$ values beyond the range, the momentum and the velocity were weakened, and the rock fragmentation decreased.

For the parameter $L$, the effect of $L$ on the rock fragmentation was nonlinear, and the $X$-value showed a decreasing trend with the increase of $L$. Due to the friction between the abrasive particles and the nozzle wall, the abrasive velocity was weakened as $L$ increased, which resulted in the reduction of the rock fragmentation. 


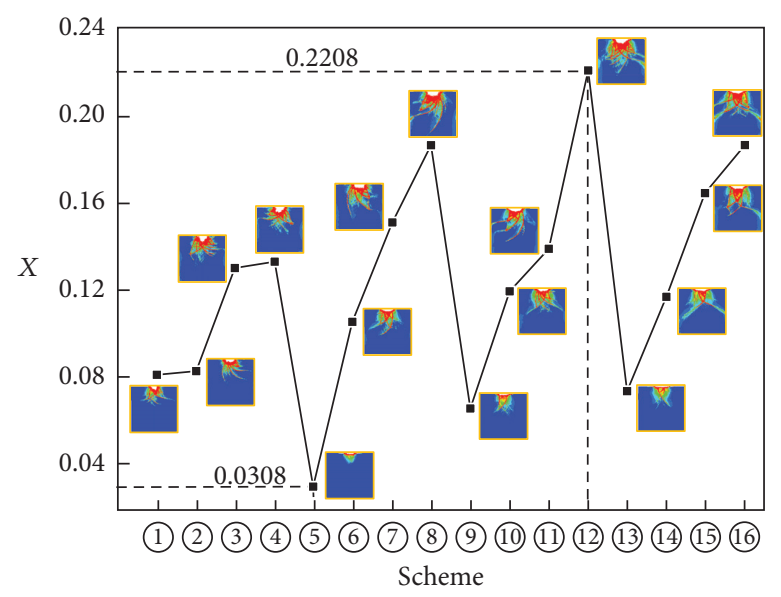

Figure 12: The distribution curve of the $X$-value under different nozzle parameter schemes.

To find the optimal parameter combination, the macrofragmentation characteristics and the $X$-values for different combination schemes were compared and analyzed. Figure 12 displays the distribution curve of the $X$-value for different nozzle parameter schemes. It can be seen from the figure that for different nozzle parameters, with the increase of the transverse and longitudinal distances, the rock fragmentations were gradually weakened, but there were certain differences in the craters and the crack extension features. For the nozzle parameter combinations of (5), (9), and (13), there was the small depth and width of the craters as well as insufficient crack propagation, without the obvious crushing. However, for other parameter combinations, the depth and the width of the craters were larger, and the cracks were fully expanded with the large crushing. According to the statistical analysis, for the parameter combination of (12), the $X$-value was 0.2208 , and the rock fragmentation was the most serious. It could be recognized that the optimum combination was that the values of $d, \alpha$, and $L$ were $3 \mathrm{~mm}, 50^{\circ}$, and $8 \mathrm{~mm}$, respectively.

For certain technical parameters of the AWJ, in this research, $X$ was proposed, and the importance ranking of the nozzle parameters, the effect of each nozzle parameter on the rock fragmentation, and the optimal combination of nozzle parameters were explored. The results could provide an effective way to optimize the nozzle structure for other different conditions and to improve the application level of AWJ technology in tunnel excavation.

\section{Conclusions}

On the basis of the coupling algorithm of SPH-FEM, this paper established the AWJ impacting rock numerical model, which was verified by the comparison of the internal and external fragmentation features of rock in the numerical simulation and the actual experiment based on the CT and image processing technology. And the failure mechanism of AWJ rock-breaking and nozzle parameter effects on the rock fragmentation were studied. The main conclusions in this paper are summarized as follows:

(1) Through analyzing the stress characteristics of typical particles in the rock model at the different stages and positions, the formation and expansion mechanisms of the crater and cracks were revealed. Results show that due to the large compressive stress and a high-density shear stress evoked by the strong impact of the AWJ, a crater was produced. With the sustained impact of the AWJ, the strong compressive action of AWJ was weakened greatly, and cracks were mainly generated by the tensile stress and the shear stress. Propagations of cracks were mainly caused by the tensile stress.

(2) Based on image processing and image segment, the comprehensive damage factor of rock $(X)$ representing the fragmentation degree was defined in this research. By comparatively analyzing $X$-values with certain technical parameters of AWJ, the effects of nozzle parameters on the rock fragmentation were also studied. Results indicate that for the simulation conditions in this research, the nozzle convergence angle $\alpha$ had a significant influence on the $X$-value, the nozzle diameter $d$ was the second most significant, and the influence of the cavity length $L$ had the smallest significance. The single parameter effect exploration indicates that the rock fragmentation increased with the increase of $d$ from $1 \mathrm{~mm}$ to $3 \mathrm{~mm}$, and an increase in the $d$-value beyond the range had not a significant improvement to $X$. The $X$-value increased linearly with the increase of $\alpha$ in the range of $20^{\circ}$ to $50^{\circ}$. The $X$-value showed a decreasing trend with the increase of $L$ from $7 \mathrm{~mm}$ to $10 \mathrm{~mm}$. Besides, with the certain technical parameters of AWJ, the optimum combination of nozzle parameters was that the values of $d, \alpha$, and $L$ were $3 \mathrm{~mm}, 50^{\circ}$, and $8 \mathrm{~mm}$, respectively. These studies provide a technical method for finding the optimal nozzle parameters under different working conditions and can help the AWJ technology to be better applied in tunnel excavation and other fields.

\section{Data Availability}

The data used to support the findings of this study are included within the article. 


\section{Conflicts of Interest}

The authors declare that they have no conflicts of interest regarding the publication of this paper.

\section{Acknowledgments}

This work was supported by the China Postdoctoral Science Foundation (Grant no. 2020M683257), the General Fund of Chongqing Natural Science Foundation (Grant nos. cstc2020jcyj-msxm3094), and the National Natural Science Foundation of China (Grant no. 51608082).

\section{References}

[1] G. Mojtaba, G. Kamran, J. Mostafa, and A. Siamak, "A multidimensional approach to the assessment of tunnel excavation methods," International Journal of Rock Mechanics and Mining Sciences, vol. 48, no. 7, pp. 1077-1085, 2011.

[2] I. Ocak and N. Bilgin, "Comparative studies on the performance of a roadheader, impact hammer and drilling and blasting method in the excavation of metro station tunnels in Istanbul," Tunnelling and Underground Space Technology, vol. 25, no. 2, pp. 181-187, 2010.

[3] A. W. Momber and R. Kovacevic, Principles of Abrasive Water Jet Machining-Generation of Abrasive Water Jets, Springer, vol. 4, no. 3, , pp. 90-93, London, UK, 1998.

[4] G.-W. Joo, T.-M. Oh, and G.-C. Cho, "Influencing factors for abrasive flow rate and abrasive flow quality of abrasive injection waterjet systems for tunnel excavation," Journal of Korean Tunnelling and Underground Space Association, vol. 16, no. 4, pp. 417-430, 2014.

[5] J.-G. Kim and J.-J. Song, "Abrasive water jet cutting methods for reducing blast-induced ground vibration in tunnel excavation," International Journal of Rock Mechanics and Mining Sciences, vol. 75, pp. 147-158, 2015.

[6] R. Kovacevic, H.-S. Kwak, and R. S. Mohan, "Acoustic emission sensing as a tool for understanding the mechanisms of abrasive water jet drilling of difficult-to-machine materials," Proceedings of the Institution of Mechanical Engineers, Part B: Journal of Engineering Manufacture, vol. 212, no. 1, pp. 45-58, 1998.

[7] R. M. Miranda and L. Quintino, "Microstructural study of material removal mechanisms observed in abrasive waterjet cutting of calcareous stones," Materials Characterization, vol. 54, no. 4, pp. 370-377, 2004.

[8] Y. Lu, S. Xiao, Z. Ge, Z. Zhou, Y. Ling, and L. Wang, "Experimental study on rock-breaking performance of water jets generated by self-rotatory bit and rock failure mechanism," Powder Technology, vol. 346, pp. 203-216, 2019.

[9] M. Sheng, Z. W. Huang, S. C. Tian, Y. Zhang, and Y. P. Jia, "CFD analysis and field observation of tool erosion caused by abrasive waterjet fracturing," Petroleum Science, vol. 17, no. 1-6, pp. 701-711, 2020.

[10] F. Ren, T. Fang, and X. Cheng, "Study on rock damage and failure depth under particle water-jet coupling impact," International Journal of Impact Engineering, vol. 139, 2020.

[11] T.-M. Oh, A. K. Prasidhi, G.-C. Cho, and J.-H. Shin, "Effect of water jet geometric parameters on rock fracturing," KSCE Journal of Civil Engineering, vol. 18, no. 3, pp. 772-779, 2014.

[12] T. Rupam, H. Sergej, C. Somnath, K. Dagmar, and S. Jiri, "Application of the pulsating and continuous water jet for granite erosion," International Journal of Rock Mechanics and Mining Sciences, vol. 126, 2020.

[13] R. Tripathi, S. Hloch, S. Chattopadhyaya, D. Klichová, and J. Klich, "Influence of frequency change during sandstone erosion by pulsed waterjet," Materials and Manufacturing Processes, vol. 35, no. 2, pp. 187-194, 2020.

[14] Z. Wang, T. Li, F. Wang, L. Guan, and R. Zhang, "Numerical simulation of polymer dispersion systems for polymer injection on offshore platforms," ACS Omega, vol. 5, no. 32, pp. 20343-20352, 2020.

[15] P. Shane and G. Jeun, "Coupling of rigid body dynamics and moving particle semi-implicit method for simulating isothermal multi-phase fluid interactions," Computer Methods in Applied Mechanics \& Engineering, vol. 200, no. 1-4, pp. 130-140, 2011.

[16] M. Mueller, S. Schirm, M. Teschner, B. Heidelberger, and M. Gross, "Interaction of fluids with deformable solids," Computer Animation and Virtual Worlds, vol. 15, no. 3-4, pp. 159-171, 2004.

[17] K. Farhoud and K. Ali, "Simulation of cavitating fluid-structure interaction using SPH-FE method," Mathematics and Computers in Simulation, vol. 173, pp. 51-70, 2020.

[18] T. Moonho and P. Taehyo, "Impact analysis of arbitrarilyshaped bodies using a finite element method and a smoothed particle hydrodynamics method," International Journal for Numerical Methods in Engineering, vol. 109, no. 10, pp. 1490-1520, 2017.

[19] A. Alessandro and E. Khamis, "3D micro-mechanical modelling of orthogonal cutting of UD-CFRP using smoothed particle hydrodynamics and finite element methods," Composite Structures, vol. 218, pp. 174-192, 2019.

[20] J. Wang, Y. Zhang, Z. Qin, S. Song, and P. Lin, “Analysis method of water inrush for tunnels with damaged waterresisting rock mass based on finite element method-smooth particle hydrodynamics coupling," Powder Technology, vol. 126, 2020.

[21] L. Li, F. Wang, T. Li, X. Dai, X. Xing, and X. Yang, "The effects of inclined particle water jet on rock failure mechanism: experimental and numerical study," Journal of Petroleum Science and Engineering, vol. 185, 2020.

[22] J. Zhao, G. Zhang, Y. Xu et al., "Mechanism and effect of jet parameters on particle waterjet rock breaking," Powder Technology, vol. 313, pp. 231-244, 2017.

[23] H. Jiang, Z. Liu, and K. Gao, "Numerical simulation on rock fragmentation by discontinuous water-jet using coupled SPH/ FEA method," Powder Technology, vol. 312, pp. 248-259, 2017.

[24] X. Ma, T. Zhu, Y. Fu, Y. Yan, and W. Chen, "Numerical simulation of rock breaking by abrasive water jet," Journal of Coastal Research, vol. 93, no. 1, pp. 274-283, 2019.

[25] R. Hou, C. Huang, and H. Zhu, "Numerical simulation ultrahigh waterjet (WJ) flow field with the high-frequency velocity vibration at the nozzle inlet," The International Journal of Advanced Manufacturing Technology, vol. 71, no. 5-8, pp. 1087-1092, 2014.

[26] N. Mohammadaliha, H. Afshin, and B. Farahanieh, "Numerical investigation of nozzle geometry effect on turbulent 3D water offset jet flows," Journal of Applied Fluid Mechanics, vol. 9, no. 4, pp. 2083-2095, 2016.

[27] N. Madhusarathi, G. T. David, and J. K. Thomas, "The effects of system and geometric parameters on abrasive water jet nozzle wear," International Journal of Machine Tools and Manufacture, vol. 42, no. 5, pp. 615-623, 2002.

[28] J. H. Timothy and R. J. Gordon, "A computational constitutive model for glass subjected to large strains, high strain rates and 
high pressures," Journal of Applied Mechanics, vol. 78, no. 5, pp. 1-9, 2011.

[29] L. J. Malvar, J. E. Crawford, J. W. Wesevich, and D. Simons, "A plasticity concrete material model for DYNA3D," International Journal of Impact Engineering, vol. 19, no. 9-10, pp. 847-873, 1997.

[30] ANSYS Incorporation, ANSYS Release 12.0 Documentation: Material Model Examples [EB/OL], ANSYS Incorporation, Canonsburg, PA, USA, 2009, https://wwwl.ansys.com/ customer.

[31] D. Z. Zhang, X. R. Zhang, J. D. Lin, and R. L. Tang, "Numerical simulation of rigid projectile's normally penetrating into granite targets," Journal of Beijing Institute of Technology, vol. 13, no. 03, pp. 308-312, 2004.

[32] G. Yang, A Study of Abrasive Particle Acceleration Process and Material-Removal Mechanism in Abrasive Waterjet Machining by SPH Coupled FEM, Shandong University, Jinan, China, 2012.

[33] J. Z. Jia, B. Li, and F. Liu, "Experimental study on mix proportion parameter optimization of cement anchoring material," Materials (Basel, Switzerland), vol. 13, no. 1, 2019.

[34] Y. Li, L. She, L. Wen, and Q. Zhang, "Sensitivity analysis of drilling parameters in rock rotary drilling process based on orthogonal test method," Engineering Geology, vol. 270, Article ID 105576, 2020. 